Int. J. Electrochem. Sci., 14 (2019) $441-452$

International Journal of

ELECTROCHEMICAL

SCIENCE

www.electrochemsci.org

\title{
Effect of Electrode Potential on the Drag Force on Gold and Polyvinyl Butyral Surfaces in a Flowing Aqueous Fluoride Solution
}

\author{
Filipas Ambrulevicius, Arunas Pulmanas, Deivis Plausinaitis, Vytautas Daujotis* \\ Institute of Chemistry, Vilnius University, 24 Naugarduko St, LT-03225 Vilnius, Lithuania \\ *E-mail: vytautas.daujotis@chf.vu.lt
}

doi: $10.20964 / 2019.01 .62$

Received: 13 April 2018 / Accepted: 8 May 2018 / Published: 30 November 2018

It is shown that positive electrical polarization reduces the drag force on gold- and polyvinyl butyral (PVB)-coated spheres immersed in a stream of aqueous sodium fluoride solution. This effect is related to a decrease in the interfacial viscosity of the solution at the positively polarized gold and PVB surfaces, as obtained from quartz resonator measurements. The decrease in viscosity at a polymercoated electrode is larger than that at a gold electrode, which is consistent with drag force measurements. The drag force reduction due to decreased interfacial viscosity at a polymer-coated metallic surface on application of an electrical potential widens the range of possible applications of this effect for active manipulation of wall-bounded liquid flows, given that the use of metal surfaces is limited by their risk of corrosion.

Keywords: Drag force, Gold surface, Polyvinyl butyral surface, Interfacial viscosity, Quartz resonator

\section{$\underline{\text { FULL TEXT }}$}

(C) 2019 The Authors. Published by ESG (www.electrochemsci.org). This article is an open access article distributed under the terms and conditions of the Creative Commons Attribution license (http://creativecommons.org/licenses/by/4.0/). 